\title{
Linking Ecotourism in Management of Botanic Garden: Social Innovation of Purwodadi BG of East Java, Indonesia
}

\author{
Herry Yogaswara ${ }^{1}$, Sanusi ${ }^{2}$, Titut Yulistyarini ${ }^{3}$ \\ yogaswaralipi@yahoo.com ${ }^{1}$, sanu001@,lipi.go.id \\ Research Center for Population, Indonesian Institute of Sciences, Jl. Jend. Gatot Subroto 10, Jakarta, 12710 , \\ Indonesia ${ }^{1}$, Research Center for Population, Indonesian Institute of Sciences, Jl. Jend. Gatot Subroto 10, \\ Jakarta, 12710, Indonesia ${ }^{1.2}$, \\ Purwodadi Botanic Garden - Indonesian Institute of Sciences, Jl. Raya Surabaya-Malang Km. 65, Pasuruan, \\ 67163 , Indonesia ${ }^{3}$
}

\begin{abstract}
Botanic gardens are institutions holding documented collections of living plants for the purposes of scientific research, conservation, display, and education [1]. In Indonesia, the Presidential decree No. 93 the year 2011 mentioned five functions of Botanic Garden, namely conservation, research, education, tourism, and environmental services. This study seeks to find out whether the management of botanical gardens that have been running so far can develop networks by applying social innovation to build awareness of the importance of plant conservation so that it can change the view of many people about botanical gardens as just a garden. This paper addresses ecotourism as a template to accommodate botanic gardens' functions equally. The three pillars of ecotourism, the sustainability of ecology, economy and social care are kept by the management but add on one element, namely social networking [2]. Within those pillars, the management of Purwodadi Botanic Garden improves the educational programme. This study examines both qualitatively and descriptively the efforts of the Purwodadi Botanic Garden. The result is obtained networking in ecotourism management is very important to achieve the function of botanic garden equally as well as reaching of the principle of ecotourism. The experience of the Purwodadi Botanic Garden Management, maintaining networking with other stakeholders through social innovation is one of crucial success.
\end{abstract}

Keywords: Ecotourism, Social Innovations, Networking, Botanic Garden. 


\section{Introduction}

Ecotourism is appraised as a type of tourism that will continue to sustain as long as nature exist. As a type of nature-based tourism, it is concluded as a tool for sustainable development. This is the main reason why many countries in the world put it into economic development, as well as one strategy for nature conservation. [3]. According to Australia's National Ecotourism Strategy, ecotourism is defined as "nature-based tourism that involves interpretation and education of the natural environment and is managed to be ecologically sustainable". Indeed, Australia and several countries are examined in terms of environmental aspects of policy formulation, legislation, development and marketing [4].

Many people consider the botanical garden only as a beautiful park. Full of plant and flowers, botanical gardens are indeed perfect were initially designed for esthetics alone. Nevertheless, most modern botanical gardens have evolved into critical scientific institutions and are they were the key for plant conservation and environmental education. [5]. The function of modern botanical gardens is more designed with the aim of conservation of plants such as seeds to preserve biodiversity. As for other problems, the need for such as raising awareness about the extension of various plant species, deforestation and climate change. Such social innovations often rank second in design priorities. However, they were very emphasized in the formulation of the goals and intentions that underlie them [6].

From an environmental education perspective, interacting and learning about conservation and landscapes becomes essential. This social innovation will provide a learning experience for visitors. With environmental education attached to the function of a botanical garden and applied to protect plants in the field, a botanical garden might be not just a beautiful garden. After all, it could expand the green yards of visitor's houses, and they could be friendlier to the broader environment [7]. Social innovation like this is an initiative that can open up opportunities to revisit complicated questions about human relations, and impacts on other species, and how these are taught, learned, unlearned and retaught [8].

During the 20th century, through botanical gardens have increasingly engaged scientific expertise and knowledge to improve and conserve our natural botanical wealth [9]. Involving, educating, and raising public awareness about the importance of plant diversity are ways in which plant conservation can be achieved. Therefore, 
many botanical garden managers need to improve mass communication and develop strategies to measure the progress of targets [10].

There were multiple programs that synergistic between the government and the botanical garden. The importance of building partnerships between botanical gardens and government goals to develop educational projects. That are stimulating habitual changes and formation responsible for the public [11]. Botanical Gardens can often highlight public education as a priority for all stakeholders. Increase knowledge of biodiversity conservation was a general stated purpose of environmental education that is continually being developed as social innovation [12].

Considering that the vision of botanical gardens under Indonesian Institute of Sciences (LIPI), and botanical gardens in general which will continue to develop as institutions based on international standards for botanical gardens, mission statements must be developed that explain how the botanical garden will work in the area of biodiversity conservation, scientific research, environmental education and revival awareness for sustainable development as well as integrating this into promoting recreation and tourism [13]. This paper will explain how one of the botanical gardens under the management and supervision of LIPI in East Java, namely the Purwodadi Botanic Garden, integrates all of its functions with the social innovation that it develops.

\section{Methodology}

This research was conducted qualitatively and descriptively by studying various innovations that can be carried out by botanical gardens, with Purwodadi Botanic Garden (Purwodadi BG) as a case example, by studying various programs that have been carried out during the last three years (2015- 2017). Environmental education as a secondary function of the botanical garden becomes interesting data that can be studied. This study could be started by asking critical questions about how botanical garden management can maintain social innovation and develop network links to build awareness of the importance of plants conservation.

\section{Results and Discussions}

\subsection{Finding}

According to data reported in several botanical gardens under the supervision of LIPI, Purwodadi BG in 2015 and 2016 had more participants of environmental 
education services than others. Figure 1 is the graph that shows how Purwodadi BG was the only one who climbed in 2016.

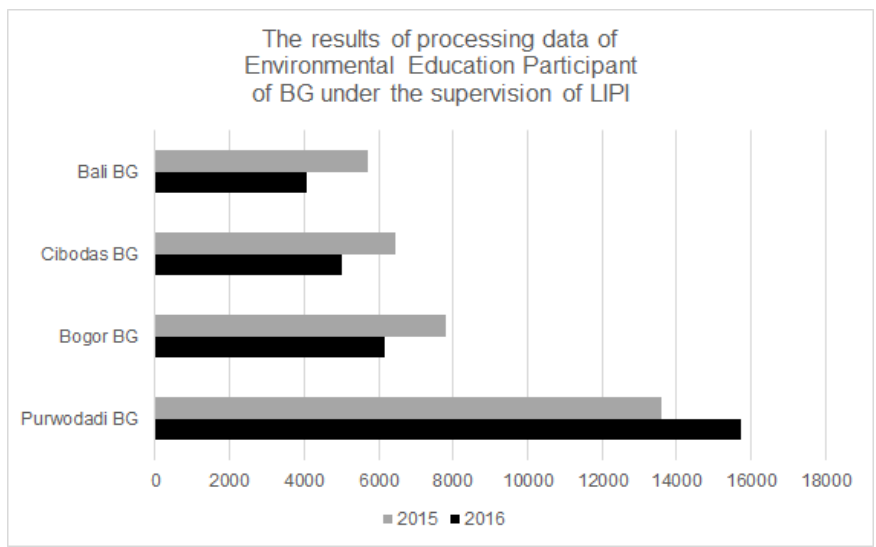

Fig. 1. Comparison of Environmental Education Participants

between Botanic Garden LIPI in 2015 and 2016

Management of the Purwodadi BG took steps to maintain the achievements in 2016 by improving the quality of environmental education services. One of them is by taking various measures to grow up the performance three steps, in the short, medium and long terms (Figure 2).

Involving the public in various environmental activities by providing educational information is a measure of the success of Purwodadi BG's performance in increasing public understanding of the importance of the environment. Purwodadi BG goes to the community to introduce environmental education programs. The aim is to promote environmental education programs managed by Purwodadi BG. The next step is to increase the promotion of environmental education programs in Purwodadi BG, the service and information unit then develops a new scheme called Good Education Programs (GE Pro).

GE Pro has a concept of combining information about a variety of plants and activities designed to complement the existing school curriculum on plant science and provide resources as learning tools for schools. Through this GE Pro, students can study modules while looking at native plants in the garden. It could increase students' motivation as an object of GE Pro users to further understand the ins and outs of plants. 


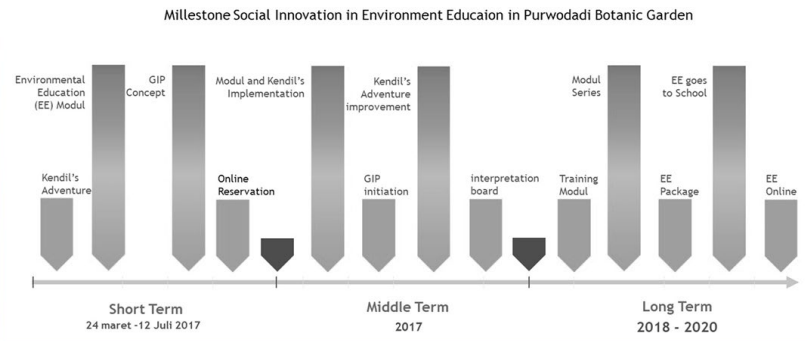

Fig. 2. Milestone Social Innovation in Environmental Education in Purwodadi Botanic Garden

Finally, GE Pro was launched in 2017 by an information and services unit tasked with managing environmental education. The program, which will be implemented at the end of 2020, consists of an Environmental Education Module, Guidance Module, Self-Guidance System, Online Reservations, and the Concept of Displaying Plantation Information Buildings (GIP). On March 24 - July 12 2017, the service and information unit carried out several activities, namely the GE Pro Outreach Program to other units and stakeholders, preparation of education and piloting modules, development of web-based independent applications, online ordering, and GIP initiation.

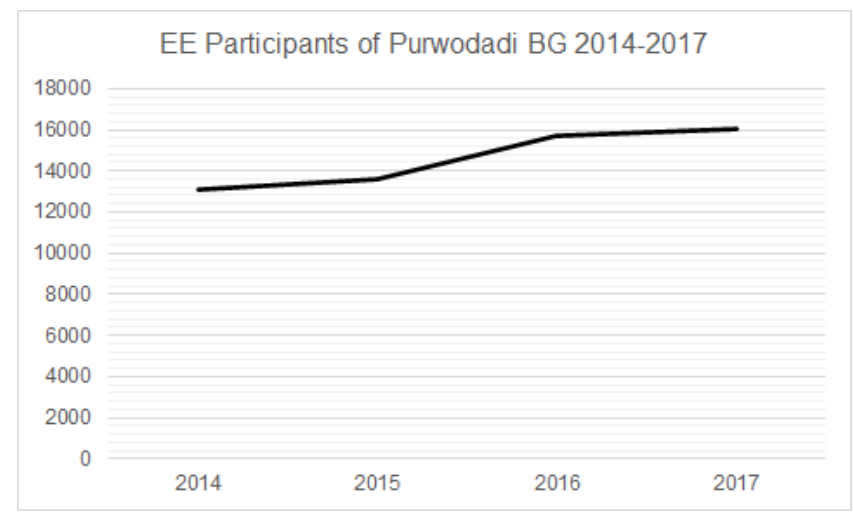

Fig. 3. Environmental Education participants 2014-2017

Until the end of 2017, the environmental education modules, guidance modules, the web base guide system, and the online reservation have been launched and tested. Promotion is carried out directly to schools, campuses, and local governments and also through social media. At the end of 2017, Purwodadi BG could retain the 
number of environmental education participants until 16021; it was still higher than the previous years (Figure 3).

After tracing the enhancement for data per month of environmental education participants, it was found that every month from 2014 to 2017, has an unstable enhancement. All are influenced by the school season and schedule. Management Purwodadi BG considers it necessary to include directly on the school agenda and deliver education on the importance of plant conservation and training how to plant propagation in schools directly (Figure 4).

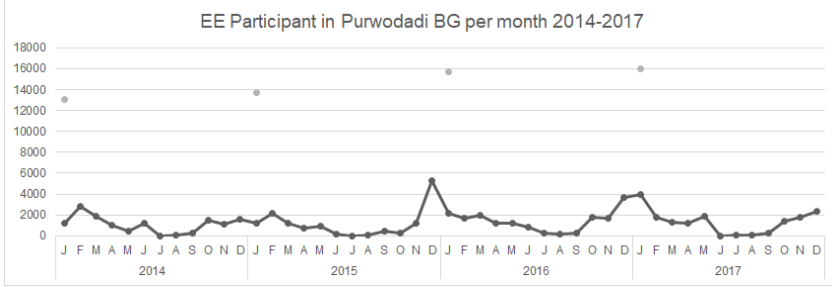

Fig. 4. Chart per month of Environmental Education participants in Purwodadi Botanic Garden 2014-2017.

\subsection{The Innovations and Networking}

Regarding the function of Purwodadi BG above, it is also essential and potential for environmental education services. The Purwodadi BG has an interest in improving the quality of environmental education services. This is contrary to the determination of Purwodadi BG to get improvements and increase the provision of assistance for its users. In providing this environmental education service, Purwodadi BG received various challenges. Based on the outcomes of a risk analysis conducted on the environmental education services process, which is claimed to have no modules, scouting is the leading risk in question. At that time, the scientific scouting material is still based on school demand and the guide, not competencies enough; there are no standard environmental education modules.

The information presented may differ between guides. Sometimes there is a mismatch between the material and the competency of the guide. Likewise, the timing of the guide cannot be predicted. The absence of a guide module also causes no material to be provided or encouraged for users. The agreed follow-up to overcome this problem is to create an environmental education module, and a pilot 
module, as well as other educational programs that can increase customer satisfaction.

Another problem is that ordering environmental education services is still done manually by getting directly or sending letters that require time and money. Thus a new mode is asked so that services are packed out more speedily and efficiently. Purwodadi BG sent an exciting display to send messages of commendation of the results of planting, plantation and research. In 2016, the Plantation Information Building (GIP) was built, but the services have not yet initiate [14].

Based on this problem, Purwodadi BG made efforts to improve the quality of environmental education services, as stated in the 2017 Performance Plan, creating innovations that are called Good Education Program (GE Pro). GE Pro contains programs to create an Environmental Education Module, a Guide Module, set up a Self-guided Guidance System, made an Online Reservation System for Environmental Education Services and develop a GIP Display Concept. Purwodadi BG has been preparing programs that are made appropriately to the needs of users, like students and communities. Also, the program is made more exciting and user friendly.

In 2017, the short-term results from GE-Pro had been launched and narrowed to the procurement of pilot modules, environmental education modules, online reservations and "kendil's adventure" systems. Procurement and manufacturing of environmental education modules are carried out for the school segment to overcome the previous problems. These problems include the diversity of material which was previously only based on the demands of each school and adjusted to the competencies of facilitators and guides available.

The guiding module book is aimed at a more extensive audience of customers, both school students and the cosmopolitan public. The two modules have been tested. Until the end of 2018 continue to be developed and disseminated to the old guides and the new guides.

In online reservations, Purwodadi BG also serves online customer reservations through Integrated Online Services named Lantern. All environmental education and guidance modules have been uploaded in the online reservation menu on the Online Service. Customers can download and choose their program package according to their needs online without having to turn in person. 
For visitors who do not want to be guided directly, they can do self-guided using a smartphone, without a guide. In 2017, Purwodadi BG introduced Kinds' Adventure System. This system is an innovative web-based independent piloting system. Creating this system is one of the alternatives in adjusting visitors whom yearning to go around the garden using internet technology. This system invites users to walk around the garden in the form of games to find locations and reach to know plant collections.

Problems faced by Purwodadi BG. In a discussion shows that environmental education is expected to provide awareness to the community, especially students about conservation. However, the development of the program in the form of GEPro, which is expected to be fun and can keep visitors, has no significant effect. It is proven that in 2017 it can only maintain the number of visitors in 16021, which is only associated with 286 visitors from the previous year.

And then in 2018, this number will drop to 12012. The GIP initiation in 2018 is not yet operational. The GIP could not be opened that year. It is because the evaluation indicated that some of the facilities in the GIP needed to be improved. The current condition of GIP as a place to draw up environmental education programs currently does not take on the required standards. Interior structuring and the creation of attractive media exposure in the building are needed to attract participants in environmental education. Likewise, media socialization needs to be reconstructed.

This problem requires the development of the Botanical Gardens to continue. Botanical gardens for a city can be a favourite tourist destination. The Botanical Gardens also continue to encourage environmental education so that people know and participate in protecting biodiversity. The Ecotourism side of Botanical gardens with their innovations must be accessible in supporting the conservation of natural resources. Clear presentation information can attain it easier for visitors to increase knowledge in the subject areas of botany, conservation, environment, and plant utilization; and to save growth, awareness, care, responsibility and community commitment to plant preservation. Ecotourism can also create nature tourism that has knowledge content while praising and inspiring it to support a better social life.

On National Education Day 2018, the Minister of Education and Culture of the Republic of Indonesia, Muhadjir Effendy and all staff also witnessed a special moment, namely the signing of the MoU between the Malang City Education Office and the Purwodadi BG as one of the closings of the collaboration between Purwodadi BG and several schools in Malang. These schools in Malang use the 
Environmental Education Module launched by Purwodadi BG. Modules made are assessed according to the school curriculum and are presented more attractively so that students understand them more easily. The Head of Malang City Education Office welcomed the program signed by Purwodadi BG. Synergy in educating the younger generation is a common goal, especially in terms of cultivating a caring and loving character for the environment. In that direction, environmental sustainability will be maintained. The presence of the Minister of Education and Culture of the Republic of Indonesia, Muhadjir Effendy at the event indirectly provided a positive atmosphere which indicated that the government was present to improve environmental education and emphasized that the character of caring for the environment must be planted from an early age through schools.

In mid-2019, the GIP was opened for further use as a prompting to spread science and technology in the eastern region of Java. This GIP facility is used as a learning medium for visitors. Assessing the success of this facility in increasing the success of environmental education and increasing visitors cannot be analyzed in a brief time. Nevertheless, at least, the GE-Pro program can be implemented according to its long-term program. This also shows that Purwodadi BG has shown social innovations in this program. GE-Pro is part of social innovation that makes collaboration intertwine with the active collaboration of constituents across government, business, and the nonprofit world.

\subsection{Social Innovation}

According to Wigboldus (2016 in Dias and Partidário 2019), there are ten different types of 'social innovation'. The illustration above briefly characterizes and gives examples of these types. This can provide an overview of various kinds of social innovation type. This type is based on the distinction of aspects of capital lines. This theory includes distinguishing between ten types of social innovation [15]. The differences across are about how the 'social' in 'social innovation' is treated and defined. 


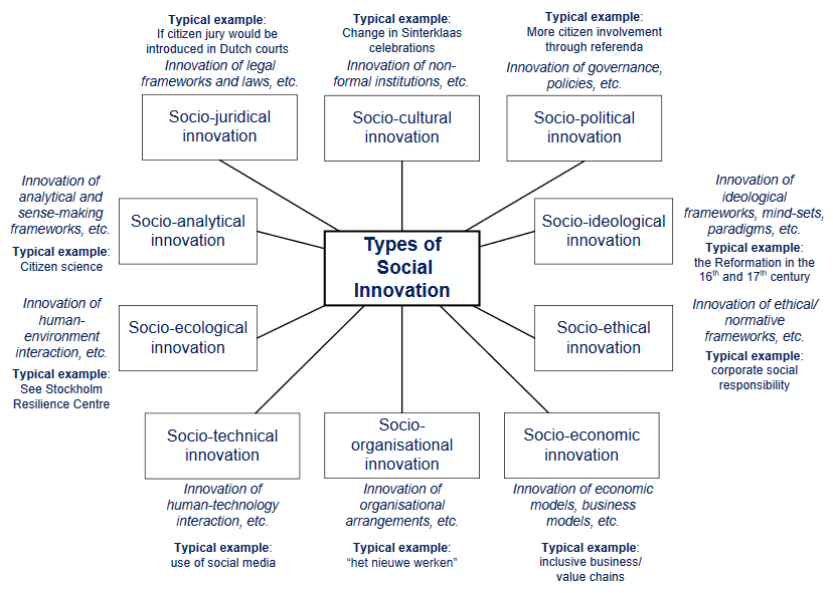

Fig. 5. Ten types of social innovation (Wigboldus, 2016)

Social innovations in the Purwodadi's BG are more likely to increase the role of information technology, in addition to the development of environmental education that uses top-down management and public relations. At different levels or scales, the type can be categorized as multiple social innovations [16].

In this case, when there is a decrease in the number of users of environmental education or ecotourism services in the Botanical Gardens, or similar tourist attractions, social and institutional network relationships need to be maintained and developed.

It is essential to know what kind of social innovation is to focus on existing problems. Mapping the problem and how to overcome it are very important in planning and in designing the recovery process. Social innovation is not only based on its emergence but must be seen as an essential part of a program.

Social innovation is sometimes considered by management only as an internal responsibility. However, social innovation that is solved is a problem that is asked by the community. The demand of the community or customers who are the target recipients of innovation are an integral part of social innovation programs. Therefore, social networks in social innovation are not only about internet networks or information technology. 


\subsection{Challenges}

The innovation in developing GE Pro poses challenges, primarily to ensure the sustainability of future launches. The challenges faced by Purwodadi BG are:

1. Facilitator competence, Perception, understanding, and competence among facilitators must be standardized so that there is no difference in delivery. Therefore, it is necessary to provide extensive internal training services for facilitators.

2. User support, so far, the school has developed its own activities that support environmental education. The presence of GE Pro is expected to overcome the difficulties of schools in developing environmental education activities. Therefore, it is necessary to support schools in order to use GE Pro services by conducting intensive promotions and introductions.

3. Continuous development of GE Pro for mid and long term implementation, the sustainability of GE Pro for mid and long term implementation is a challenge for Purwodadi BG. Maintaining and improving the quality of service for all products in GE Pro is a must. All GE Pro products must be developed, upgraded, diversified, and services extended.

4. Limited budget, collaborating with the private sector in the form of partnerships is one of the efforts taken by Purwodadi BG in order to obtain funding to support the development of a dynamic display of GE Pro services and exhibition costs are projected to be very high.

\section{Conclusion}

Social innovation in ecotourism is very significant. Determining the type of social innovation will be very helpful in answering what people want. Community users ask become the fundamental part of the planning steps of social innovation programs in ecotourism, such as in the botanical garden.

In this case, Purwodadi BG continues to innovate through the use of information technology to support program improvements and expansion of social networks as an integral part of program implementation. However, the main thing that supports Purwodadi BG's success in developing environmental education is a strong commitment to promoting knowledge and care for nature. GE Pro services are the tools Purwodadi BG uses to prove this commitment. GE Pro assists Purwodadi BG 
by engaging the younger generations to form emotional bonds with plants and nature as a tool to promote understanding and conservation of Indonesian plants to the broader general public.

Acknowledgments Our thanks to Purwodadi BG management for allowing us for this research. We declare all of the authors have equal contributions, and all of the authors declare no conflicts of interest in this study.

\section{References}

[1] Jackson, P. W. and Sutherland, L.A. International agenda for botanic gardens in conservation. Richmond, England: Botanic Gardens Conservation International. 2000.

[2] Damanik, J. and Weber, H. Perencanaan Ekowisata: Dari Teori ke Aplikasi. Yogyakarta: Andi Offset. 2006.

[3] Açıksöz, S., Cetinkaya, G.C., Uzun, O., Nemutlu, F.E., \& Ilke, E.F. Linkages among ecotourism, landscape and natural resource management, and livelihood diversification in the region of Suğla Lake, Turkey. International Journal of Sustainable Development \& World Ecology, 23, (September, 2015), 15 - 27. 2016.

[4] Barkin, D. Ecotourism: A tool for sustainable development in an era of international integration? In Miller, J. A., and Malek-Zadeh, E., (eds.), The Ecotourism Equation:Measuring the Impacts. Yale Bulletin Series, No. 99. Yale University, New Haven, pp. 263-272. 1996.

[5] Fullard, D. Ecotourism and Botanic Gardens - An ecotourism perspective. Paper presented at the 3rd Global Botanic Gardens Congress held in Wuhan. 2007.

[6] Tal, R.T. Using A Field Trip To A Wetland As A Guide For Conceptual Understanding In Environmental Education - A Case Study of A Pre-Service Teacher's Research. Chemistry Education, Research and Practice I5,2 (May, 2004), 127-142. DOI=https://doi.org/10.1039/B4RP90016B. 2004.

[7] Błaszak, M., Rybska, E., Tsivitanidou, O., Constantinou, C.P. Botanical Gardens for Productive Interplay between Emotions and Cognition. Sustainability 11, 24 (Decemberc, 2019) 1-20. DOI=https://doi.org/10.3390/su11247160. 2019.

[8] Sanders, D.L., Ryken, A.E., and Stewart, K. Navigating nature, culture and education in contemporary botanic gardens, Environmental Education Research, 24,8(May, 2018), 1077-1084, DOI:=https://doi.org/10.1080/13504622.2018.1477122. 2018.

[9] Cannon, C. H., \& Kua, C. S. Botanic gardens should lead the way to create a "Garden Earth" in the Anthropocene. Plant diversity, 39(6), (November, 2017), 331-337. DOI=https://doi.org/10.1016/j.pld.2017.11.003.2017. 
[10] Cerati, TM. Education and training in Brazilian botanical gardens: are we achieving GSPC. Rodriguésia, 69, 4, (December, 2018),1603-1612. DOI=https://doi.org/10.1590/2175-7860201869410. 2018.

[11] Sharrock, S., Hoft, R., and Dias, B.F.S. An overview of recent progress in the implementation of the Global Strategy for Plant Conservation - a global perspective. Rodriguésia, 69, 4, (December, 2018), 1489-1511. DOI=https://doi.org/10.1590/21757860201869401.2018.

[12] Williams, S.J., Jones, J.P.G., Gibbons, J.M. et al. Botanic gardens can positively influence visitors' environmental attitudes. Biodivers Conserv 24, (July, 2015), 1609-1620. DOI=https://doi.org/10.1007/s10531-015-0879-7. 2015.

[13] Chen, G., \& Sun, W. The role of botanical gardens in scientific research, conservation, and citizen science. Plant diversity, 40(4), 181-188. (Julyi 2018). DOI=https://doi.org/10.1016/j.pld.2018.07.006. 2018.

[14] Yulistyarini, T. Good Education Programmes (GE Pro): Layanan Jasa dan Informasi Kebun Raya Purwodadi-LIPI. Cibinong. Pusbindiklat Peneliti LIPI. 2017.

[15] Wigboldus, S. Ten Types of Social Innovation-A Brief Discussion Paper. Available online: https://library.wur.nl/WebQuery/wurpubs/fulltext/407981 (accessed on July 21, 2020). 2016.

[16] Hapsari L, Yulistyarini T. Purwodadi Botanic Garden Good Education Programmes: engaging students, teenagers and community. Roots BGCI 14(2): 28-31 (accessed on July $212020) .2018$.

[17] Dias, J. ve Partidário, M. Mind the Gap: The Potential Transformative Capacity of Social Innovation. Sustainability, 11(16), 4465. DOI=https://doi.or/10.3390/su11164465. 2019. 